\title{
Frequency of IgE-dependent hypersensitivity to moulds in patients with chronic rhinosinusitis with polyps
}

\author{
Radosław Gawlik ${ }^{1}$, Eugeniusz Czecior², Jerzy Jarząb ${ }^{3}$, Alicja Grzanka³ , Ewelina Cichecka ${ }^{4}$, Paweł Sowa², \\ Wojciech Ścierski
}

\author{
${ }^{1}$ Chair and Clinical Department of Internal Diseases, Allergology and Clinical Immunology, Medical University of Silesia, Katowice, Poland \\ Head of Department: Prof. Barbara Rogala MD, PhD \\ ${ }^{2}$ Chair and Clinical Department of Otolaryngology in Zabrze, Medical University of Silesia in Katowice, Poland \\ Head of Department: Prof. Grzegorz Namysłowski MD, PhD \\ ${ }^{3}$ Clinical Department of Internal Diseases, Dermatology and Allergology in Zabrze, Medical University of Silesia in Katowice, Poland \\ Head of Department: Prof. Jerzy Jarząb MD, PhD
}

${ }^{4}$ Outpatient Allergy Clinic Novomed, Czestochowa, Poland

Postep Derm Alergol 2014; XXXI, 3: 159-163

DOI:10.5114/pdia.2014.40976

\begin{abstract}
Introduction: The complicated etiology of chronic sinusitis with polyps and frequent allergy to mould is established. Aim: We aimed to investigate the frequency of the IgE-dependent hypersensitivity in this group of patients and prove the need of surgery in allergic chronic rhinosinusitis patients.

Material and methods: Forty-two patients (19 females, 23 males) aged $34-73$ years ( $55 \pm 12.6$ years), with chronic sinusitis with polyps were included into the study. Functional endoscopic sinus surgery, laryngological examination, sinus computed tomography scans, and smear from maxillary sinus for microbiological examination were done in all patients. Skin prick tests with common perennial and seasonal inhalant allergens, tlgE and slgE against moulds were required.

Results: Thirty-two of 42 patients (71.4\%) were allergic to at least one inhalant allergen. A mean concentration of total IgE was $241.2 \pm 186.3 \mathrm{kU} / \mathrm{l}(35.0-708.0 \mathrm{kU} / \mathrm{l})$ and was lower in patients with fungal culture found in sinus mucin than in patients without fungal presence $75.1 \pm 54.6 \mathrm{kU} / \mathrm{l} \mathrm{vs} .284 .3 \pm 204.1 \mathrm{kU} / \mathrm{l}$. We found no difference in the number of positive skin prick tests in a group with and without fungal culture. None of patients with fungal culture found in sinuses presented a detectable level of mold slgE. All patients with fungal vegetation in sinuses required at least two polypectomy procedures.

Conclusions: The total IgE concentration was significantly lower in patients with fungal presence in sinuses. Nasal polyps occurred more frequently in patients with fungal presence in sinuses.
\end{abstract}

Key words: chronic rhinosinusitis, mould allergy, IgE, nasal polyps.

\section{Introduction}

Sensitivity to fungal allergens plays an important role in the pathogenesis of allergic rhinitis, asthma, and sinus diseases all over the world [1-3]. We observe an increasing rate of chronic rhinosinusitis (CRS) presence. According to data assembled in the USA in 1997, acute and chronic sinusitis t concerned $14 \%$ of population [4]. Even with the development of diagnostic tools, we still do not know the precise prevalence of chronic sinusitis. In the USA, in 1996, chronic sinusitis accounted for 32 million patient visits [5]. It means that chronic sinusitis influences the quality of life of many patients every year, caus- ing important economic implications [6]. Epidemiological analysis reveals that in some of those CRS patients, IgE-dependent hypersensitivity is present. On the other hand, in $25-30 \%$ of allergic patients, $43 \%$ of asthmatics, chronic sinusitis can also be found [5]. In the previous data, there is contrary information about the frequency of allergy occurrence in CRS patients versus CRS-free subjects [7]. Chronic sinusitis is the most common cause of nasal polyps. Allergic state of eosinophilic inflammation is involved in polyp formation in a great part of patients. Current studies do not conclusively demonstrate a causal relationship of airborne mold and clinical manifestation of CRS. Data are indirect and conflicting.

Address for correspondence: Radosław Gawlik MD, PhD, Assoc. Prof., Chair and Clinical Department of Internal Diseases, Allergology and Clinical Immunology, Medical University of Silesia, 15 Poniatowskiego St, 40-055 Katowice, Poland, phone: +48 601 464786, e-mail: radwags@poczta.onet.pl Received: 27.12.2013, accepted: 14.01.2014. 
In recent years, there has been an increase in occurrence of fungal infections related with chronic rhinosinusitis. This fact is linked with many promoting factors, such as diabetes mellitus, steroid therapy, antibiotics, and immunosuppression use etc. Molds may of course cause an infection. Improvement in diagnostic procedures allow to identify this kind of infections. The most common pathogen in those situations is aspergillus fumigatus and aspergillus flavus [8-10]. But the presence of fungal spore itself is not decisive in diagnosis, because in many healthy individuals it may also be present in the sinus smear.

Airborne fungi and their spores are ubiquitous. The most common illness caused by a mould spore is allergic rhinitis [11-19]. Allergic rhinitis is usually connected with a similar process in sinuses and may proceed into chronic rhinosinusitis. The widespread research in the whole population revealed that the most common serum fungal antibody was slgE against Alternaria species, present in $7 \%$ of population [8].

Further analysis concerning occurrence of mold spores in internal and external human environment revealed that the most frequent mold spores are the following: Alternaria alternata, Cladosporium herbarum, Cladosporium cladosporioides, Aspergillus niger, Penicillium chrysogenum. According to Spanish authors, these molds constitute up to $85.5 \%$ of all mould colonies grown from different air samples taken from the environment of patients with allergy to mould [10, 12].

The present data about immunology of nasal mucosa, and the role of IgE, IgG and mastocytes in the mechanisms of hypersensitivity are not fully conclusive. They reveal the need of further research on pathomechanisms of chronic sinusitis [4, 6, 10, 13-15]. Moreover, the question if moulds and which of them are clinical important allergens in chronic sinusitis development, needs to be answered.

The complicated etiology of chronic sinusitis with polyps and frequent allergy to mould lead us to perform the research on frequency of occurrence of the IgE-dependent hypersensitivity in this group of patients.

\section{Aim}

The aim of the study was to assess the frequency of the IgE dependent hypersensitivity to inhalant allergens especially to mould in patients with chronic sinusitis with polyps.

\section{Material and methods}

In the study, 42 patients (19 females, 23 males) aged 34-73 years ( $55 \pm 12.6$ years), with chronic sinusitis with polyps, after sinus surgery in the ENT Department in Zabrze from February to July 2011 were included. All of them had at least one functional endoscopic sinus surgery (FESS). The diagnosis was confirmed by interview,
ENT examination and sinus computed tomography (CT) scans. All patients met the radiological criteria of sinusitis and sinunasal mucus was obtained during surgery. Among those patients, 8 suffered from asthma and in 10 patients allergic rhinitis was diagnosed on the basis of patient history, skin prick tests, and pulmonary function tests. None of patients developed immunodeficiency disease, diabetes, cystic fibrosis or immobile ciliary syndrome. The previous course of the illness or additional tests (CT, nasal smear) excluded the fungal infection. None of the patients were treated with oral corticosteroids or leukotriene antagonists.

\section{Skin prick tests}

In all patients qualified for the study, allergy skin testing with common perennial and seasonal inhalant allergens including: grass/cereal, grass, weed, rye, trees I, trees II, Candida albicans, Dermatophagoides pteronyssinus, Dermatophagoides farinae, dog's and cat's fur, Alternaria alternata, Cladosporium herbarium, mould's mix I (Botrytis cinerea, Cladosporium herbarum, Curvularia lunata, Fusarium moniliforme, Helminthosporium), mould's mix II (Aspergillus fumigatus, Mucom mucedo, Penicillium notatum, Rhizopus nigricans, Serpula lacrymans, Pullularia pullulans) (Allergopharma, Reinbek, Germany) was performed. The concentration of all allergen solution was $10000 \mathrm{TE} / \mathrm{ml}$. The tests were read after $15 \mathrm{~min}$. The size of the wheal was measured in millimeters and compared with the control solution and histamine. A positive SPT was defined as a wheal equal to or larger than $5 \mathrm{~mm}$ at diameter.

\section{Immunological assay}

Blood samples for immunologic assessments were drawn from cubital vein. In all patients, the concentration of allergen specific IgE for Alternaria alternata, Cladosporium herbarium, Penicillium notatum, Aspergillus fumigates and total IgE concentration was determined with the ELISA method (Omega Diagnostics PLC, UK).

\section{Microbiological examination}

In all patients, the smear from maxillary sinus was done under sterile conditions during surgery (FESS). The culture was taken from the sinus site affected. The samples were incubated on plates (Biocorp, Poland) on three kind of medium: Sabouraud's dextrose agar with Chloramphenicol Lab-Agar $\left(26^{\circ} \mathrm{C}\right.$ and $\left.37^{\circ} \mathrm{C}\right)$, Czapek-dox Lab-Agar $\left(26^{\circ} \mathrm{C}\right.$ and $\left.37^{\circ} \mathrm{C}\right)$ and Candida Chromogenic LabAgar $\left(37^{\circ} \mathrm{C}\right)$. Assays were performed in the Microbiological Laboratory of the Department of Internal Diseases, Dermatology and Allergology, Zabrze.

\section{Statistical analysis}

Independent sample t-tests were determined. Results with values of $p<0.05$ were considered significant. 
Table 1. Number of patients with positive reactivity to inhaled allergens

\begin{tabular}{lccccccc}
\hline Allergens & $\begin{array}{c}\text { House dust } \\
\text { mite }\end{array}$ & Grass & Weed & Rye & Trees I & Trees II & Dog's fur Cat's fur \\
\hline $\begin{array}{l}\text { Number } \\
\text { of patients }\end{array}$ & 21 & 12 & 9 & 15 & 9 & 6 & 3 \\
\hline
\end{tabular}

\section{Results}

\section{Skin tests}

Thirty-two of 42 patients (71.4\%) were allergic to at least one inhalant allergen, mostly to house dust mite and molds (Table 1). Moreover, 14 patients had positive tests for mould as follows: Alternaria-10, Cladosporium - 5, Candida albicans - 8, Penicillium notatum - 5, Aspergillus fumigates -6 , other mould tests were negative.

\section{Measurement of antibodies IgE to mold and tlgE}

Measurements of slgE for selected fungi provided only 4 positive results for Alternaria alternate (all $<0.7 \mathrm{kU} / \mathrm{l}$ ), none in recurrent sinus surgery patients, all other results were negative $(<0.35 \mathrm{kU} / \mathrm{l})$. The mean concentration of total IgE was $241.2 \pm 186.3 \mathrm{kU} / \mathrm{l}$, but the range was wide between $35.0 \mathrm{kU} / \mathrm{l}$ and $708.0 \mathrm{kU} / \mathrm{l}$. None of patients with positive microbiological examination of mucus had positive skin tests for mold allergens and there was no presence of specific IgE against mold either. The mean concentration of total IgE in this group of patients was $75.1 \pm 54.6 \mathrm{kU} / \mathrm{l}$ and was significantly lower compared with patients without fungal infection $284.3 \pm 204.1 \mathrm{kU} / \mathrm{l}$ $(p<0.05)$ (Figure 1).

Moreover, in patients with positive fungal culture sinus, surgery was performed more often (5.3 vs. 2.2 times) than in patients whose culture from sinus surgery specimens did not contain moulds (Table 2) ( $p<0.05)$. None of all 42 patients had verified fungal hyphae in pathologic examination.

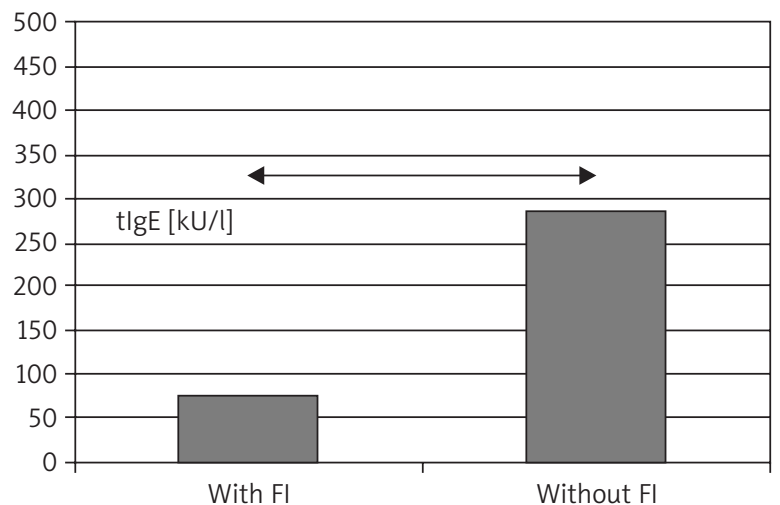

Figure 1. Mean total lgE level in chronic rhinosinusitis patients with and without fungal infection (FI)

\section{Microbiological examination}

After incubation of samples obtained from sinuses during the surgery, in 10 patients ( 2 females and 8 males), the fungal culture was found. On the Sabouraud's dextrose agar medium with chloramphenicol plates, Candida albicans, Aspergillus fumigates and Aspergillus niger vegetation were identified. Eosinophilic mucin was detected in $86 \%$ of patients.

\section{Discussion}

Rhinosinusitis, acute or chronic, is a disease affecting a significant proportion of the world population

Table 2. Characteristics of patients with fungal culture positive examination of the smear taken from sinuses

\begin{tabular}{|c|c|c|c|c|c|c|}
\hline $\begin{array}{l}\text { Patient's } \\
\text { age [years] }\end{array}$ & Gender & $\operatorname{tlgE}[\mathrm{kU} / \mathrm{ll}]$ & $\begin{array}{l}\text { slgE (kU/l) } \\
\text { (mould) }\end{array}$ & Skin tests & FESS account & Other diseases \\
\hline 71 & $\mathrm{~F}$ & 89 & 0 & 0 & 4 & Asthma \\
\hline 73 & M & 35 & 0 & 0 & 8 & Aspirin hypersensitivity \\
\hline 35 & M & 110 & 0 & $\begin{array}{c}\text { Grass and house } \\
\text { dust }\end{array}$ & 12 & Aspirin hypersensitivity \\
\hline 62 & M & 90 & 0 & 0 & 2 & \\
\hline 40 & M & 93 & 0 & $\begin{array}{c}\text { Weed and house } \\
\text { dust }\end{array}$ & 4 & \\
\hline 73 & M & 48 & 0 & 0 & 2 & \\
\hline 58 & $\mathrm{~F}$ & 78 & 0 & 0 & 3 & Asthma \\
\hline 54 & M & 112 & 0 & House dust & 4 & \\
\hline 47 & $M$ & 58 & 0 & 0 & 2 & Aspirin hypersensitivity \\
\hline 72 & M & 38 & 0 & House dust & 5 & Asthma \\
\hline
\end{tabular}


$[4,6,13]$. According to the Centers for Disease Control and Prevention (CDC), the current prevalence of sinusitis in the US is up to $13.4 \%$ of the population (29.5 million adults) [16]. Significance of allergic reaction in chronic rhinosinusitis is still controversial. Chronic rhinosinusitis inflammation is predominantly mediated by eosinophils in Western populations. Eosinophil as an important mediator of allergic reaction indicates related allergic problems. The presence of eosinophilic polyps accompanying chronic sinusitis is not identical with diagnosis of allergy and must not be a symptom of allergy. However, in CRS only $40-60 \%$ of patients have a positive allergy test, and the eosinophilic inflammation is present with the same intensity in patients who have detectable IgE-mediated allergies as in those that do not [17]. Fungal organisms are widespread on the Earth, and are one of the most common group of aeroallergens. Spores are the most allergic parts of molds. It is known that molds play an important role in the pathomechanism of allergic rhinitis, but their complicated role in chronic sinusitis is still not clearly understood and brings us often controversial opinions [7, 18, 19]. A different hypothesis concerns the state of allergic fungal rhinosinusitis. The latest research shows that allergy to mould allergens is present in $5-30 \%$ of people with atopy [11]. In $10 \%$ of patients, spores are the causative factor of chronic rhinosinusitis. The symptoms are not induced by fungal invasion, but allergic stimulation of mucosa [20]. It is shown that in patients with CRS, dendritic cells, mastocytes, lymphocytes respond to inhaled mould spores. A ubiquitous airborne mold Alternaria alternata induces production of cytokines IL-5 and IL-13 that are responsible for development of eosinophilic inflammation and an increase in slgG [17]. Alternaria is present in CRS patients as well as in healthy controls. However, only the immune cells of CRS patients react to the presence of Alternaria with the production of cytokines crucial for inciting the eosinophilic inflammation seen in this disease. This cytokine-driven immune response occurs independently of IgE production [17]. The non-IgE mediated lymphocyte response should also be considered. A correlation between an increase in serum IgG concentration and IL-5 release was also observed [16]. Patients with CRS presented 5 times higher IgG concentration in the serum than healthy individuals [17]. Moreover, it was shown that one of protein fractions extracted from Alternaria alternata can elicit direct eosinophil degranulation [21]. Other mould allergens have no such a feature, moreover have no influence on neutrophils. This observation suggests possible specific immune response to mould species in human beings [17, 21]. It has been suggested that allergy to Alternaria moulds is a marker of hypersensitivity to many other spores [20-22]. A recorded number of positive skin prick tests to Alternaria in CRS patients was higher compared to healthy population. The frequency of positive skin tests to mould allergens was observed in $33 \%$ of patients in our study and was similar to results of other authors [20, 22]. In asthmatic patients this frequency was even higher - of over $50 \%$. These responses to ubiquitous airborne fungi may explain both the chronic airway inflammation and the concomitant asthma in patients with CRS. In the current study, $71.5 \%$ of patients with chronic rhinosinusitis with polyps presented positive skin tests to main inhaled allergens. This result shows more frequent occurrence of hypersensitivity to inhaled allergens compared to the whole population (i.e. 30-40\%) [11, 12]. There are some reports that asthma is related with the risk of moulds occurrence and fungal allergy. Positive skin tests to mould allergens were observed in $60 \%$ of asthma patients in Gdansk [23]. Some authors suggest that frequency of fungus occurrence in healthy people and CRS patients is similar and reaches about 100\% $[5,7]$. It implies that presence of fungi is an insufficient factor responsible for pathogenesis of CRS. On the other hand, Tonus et al. and Różańska-Kudelska et al. did not support these results [24, 25]. However, Ponikau et al. found a similar high percentage of fungal cultures from nasal lavage content in CRS patients and controls, which reflects the fact that they were all indeed inhaling fungal spores [26]. The findings of this study reveal a relationship between mould presence in the sinuses and multiple polypectomy. The incidence of allergic hypersensitivity to inhaled moulds was not significant for chronic rhinosinusitis. Similar results were presented by Hidir et al. in their study [27].

Saprophytic sinus infection is a state of noninvasive sinusitis. This state is characterized by asymptomatic sinusitis, which is common in CRS patients after several surgeries [13]. Our results support this fact, because patients with positive fungal culture have FESS more frequently. In our material, in almost $1 / 4$ of operated patients, we confirmed the fungus presence in mucin recovered from sinuses (Candida albicans, Aspergillus fumigates and Aspergillus niger). In those patients neither the interview nor the laryngological examination and CT scans suggested fungal co-infection. Noninvasive saprophytic fungal infection may be responsible for those results. Identification of fungus in postoperative material may be important for the follow-up and further treatment $[13,15,27]$. It is interesting that none of fungi-positive patients demonstrated hypersensitivity to molds in skin prick tests or slgE assay. This group of patients presented a 4-fold lower level of tlgE than patients with numerous polypectomy.

There is an increasing number of mould allergic patients in the current medical practice. When making a diagnosis of mould allergy we have to remember that some selected mould allergens are clinically important and essential to cause the allergic inflammation of nasal mucosa or conjunctiva.

Atopic reactivity predispose rhinosinusal mucosa to more frequent infections. An increased serum concen- 
tration of total IgE in all investigated patients with CRS, as observed in our study, supports this opinion. It is also supported by other authors. Hutcheson et al. described a 5 -times higher concentration of tIgE in CRS patients [28]. Different results of total IgE and fungal slgE serum concentration in patients with fungal sinus presence may suggest that immunoglobulin $\mathrm{E}$ is not linked to the development of fungal presence in patients with chronic rhinosinusitis with nasal polyps. Possibly mechanisms other than type I hypersensitivity are crucial in the development of such pathology.

In the future, further research using larger sample sizes and more quantitative analysis techniques should be done. Clinicians should be aware that presence of fungi in sinuses coexist with recurrent evolution of nasal polyps.

\section{Conclusions}

The total IgE concentration was significantly lower in patients with fungal presence in sinuses compared to those without. Patients with fungal presence in sinuses have nasal polyps more often and need to undergo surgery more frequently. The presence of mould increases the risk of nasal polyps. Allergy to inhaled allergens often coexists with CRS with polyps.

\section{Conflict of interest}

The authors declare that they have no interests to disclosure that are relevant to this publication.

\section{References}

1. Żukiewicz-Sobczak WA, Cholewa G, Krasowska E, et al. Grain dust originating from organic and conventional farming as a potential source of biological agents causing respiratory diseases in farmers. Postep Derm Alergol 2013; 30: 358-64.

2. Żukiewicz-Sobczak WA, Cholewa G, Krasowska E, et al. Rye grains and the soil derived from under the organic and conventional rye crops as a potential source of biological agents causing respiratory diseases in farmers. Postep Derm Alergol 2013; 30: 373-8.

3. Sowa P, Rutkowska-Talipska J, Rutkowski K, et al. Optical radiation in modern medicine. Postep Derm Alergol 2013; 30: 246-51.

4. Kaliner MA. Sinusitis: bench to bedside. Otolaryngol Head Neck Surg 1997; 100: 510-4.

5. Van Cauwenberge P, Watelet JB. Epidemiology of chronic rhinosinusitis. Thorax 2000; 55 (Suppl 2): S20-1.

6. Anand VK. Epidemiology and economic impact of rhinosinusitis. Ann Otol Chinol Laryngol Suppl 2004; 193: 3-5.

7. Ponikau JU, Sherris DA. The role of airborne mold in chronic rhinosinusitis. J Allergy Clin Immunol 2006; 118: 762-3.

8. Gergen PJ, Turkeltaub PC. The association of individual allergen reactivity with respiratory disease in a national sample: data from the second National Health and Nutrition Examination Survey, 1976-80 (NHANES II). J Allergy Clin Immunol 1992; 90: 579-88.

9. Soler ZM, Schlosser RJ. The role of fungi in diseases of the nose and sinuses. Am J Rhinol Allergy 2012; 26: 351-8.
10. Hsu J, Peters AT. Pathophysiology of chronic rhinosinusitis with nasal polyp. Am J Rhinol Allergy 2011; 25: 285-90.

11. Mari A, Schneider P, Wally V, et al. Sensitization to fungi: epidemiology, comparative skin tests, and IgE reactivity of fungal extracts. Clin Exp Allergy 2003; 33: 1429-38.

12. de Ana SG, Torres-Rodriguez JM, Ramirez EA, et al. Seasonal distribution of Alternaria, Aspergillus, Cladosporium and Penicillium species isolated in homes of fungal allergic patients. J Investig Allergol Clin Immunol 2006; 16: 357-63.

13. Chakrabarti A, Denning DW, Ferguson BJ. Fungal Rhinosinusitis: a categorization and definitional schema addressing current controversies. Laryngoscope 2009; 119: 1809-18.

14. Gawlik R, DuBuske L. Mediator release of neuropeptides after nasal provocation in perennial allergic rhinitis patients. Rhinology 2010; 48: 2006-10.

15. Dykiewicz MS, Hamilos DL. Rhinitis and sinusitis. J Allergy Clin Immunol 2010; 125: 103-15.

16. Pleis JR, Lethbridge-Çejku M. Summary health statistics for U.S. adults: national health interview survey, 2005, National Center for Health Statistics, Vital Health Stat 10, 2006; 232: $1-153$.

17. Shin SH, Ponikau JU, Sherris DA, et al. Chronic rhinosinusitis: and enhanced immune response to ubiquitous airborne fungi. J Allergy Clin Immunol 2004; 114: 1369-75.

18. Bush RK, Portnoy JM, Saxon A, et al. The medical effects of mold exposure. J Allergy Clin Immunol 2006; 117: 326-33.

19. Lieberman A, Rea W, Curtis L. Adverse health effects of indoor mold exposure. J Allergy Clin Immunol 2006; 118: 763.

20. Manning SC, Holman M. Further evidence for allergic pathophysiology in allergic fungal sinusitis. Laryngoscope 1998; 108: 1485-96.

21. Inue Y, Matsuzaki Y, Shin SH, et al. Non-pathogenic, environmental fungi induce activation and degranulation of human eosinophils. J Immunol 2005; 175: 5439-47.

22. Hidir Y, Tosun F, Saracli MA, et al. Rate of allergic fungal etiology of chronic rhinosinusitis in Turkish population. Eur Arch Otorhinolaryngol 2008; 265: 415-9.

23. Niedoszytko M, Chełmińska M, Jassem E. Clinical value of nasal provocation in diagnosis of fungal allergy. Postep Derm Alergol 2010; 27: 214-6.

24. Tonus F, Saracli MA, Caliskander Z, Sengul A. Intranasal fungi and chronic rhinosinusitis: what is a relationship? Ann Otol Rhinol Laryngol 2007; 116: 425-9.

25. Różańska-Kudelska M, Sienkiewicz A, Południewska B, et al. Grzyby pleśniowe i rola alergii na grzyby w przewlekłym zapaleniu błony śluzowej nosa i zatok przynosowych [Polish]. Otolaryngol Pol 2009; 63: 245-8.

26. Ponikau JU, Sherris DA, Kern EB, et al. The diagnosis and incidence of allergic fungal sinusitis. Mayo Clin Proc 1999; 74: 877-84.

27. Hidir Y, Tosun F, Saracli MA, et al. Rate of allergic fungal etiology of chronic rhinosinusitis in Turkish population. Eur Arch Otorhinolaryngol 2008; 265: 415-9.

28. Hutcheson PS, Schubert MS, Slavin RG. Distinctions between allergic fungal rhinosinusitis and chronic rhinosinusitis. Am J Rhinol Allergy 2010; 24: 405-9. 